\title{
Aircraft Aeroservoelastic Modelling of the FLEXOP Unmanned Flying Demonstrator
}

\author{
Yasser M. Meddaikar*, Johannes K. S. Dillinger*, Thomas Klimmek*, Wolf R. Krüger ${ }^{\dagger}$, \\ German Aerospace Center (DLR) - Institute of Aeroelasticity \\ Göttingen, 37073, Germany \\ Matthias Wüstenhagen ${ }^{\ddagger}$, Thiemo Kier ${ }^{\ddagger}$, \\ German Aerospace Center (DLR) - Institute of Systems Dynamics $\&$ Control \\ Wessling, 82234, Germany \\ Andreas Hermanutz ${ }^{\S}$, Mirko Hornung \\ Technical University of Munich - Institute of Aircraft Design \\ Garching b. München, 85748, Germany \\ Vladyslav Rozov", Christian Breitsamter**, \\ Technical University of Munich - Chair of Aerodynamics and Fluid Mechanics \\ Garching b. München, 85748, Germany \\ James Alderman ${ }^{\dagger \dagger}$, \\ Airbus Group Innovations, BS34 7QW, United Kingdom \\ Béla Takarics ${ }^{\ddagger}$, Bálint Vanek ${ }^{\S \S}$, \\ MTA SZTAKI - Hungarian Academy of Sciences, Budapest, 1111, Hungary
}

\begin{abstract}
This paper presents the aeroservoelastic modelling toolchain established for the aircraft design exercise within the European research project, FLEXOP. The FLEXOP project aims to develop and apply active flutter suppression and load alleviation techniques on an unmanned flying demonstrator. The developed methods are then to be applied in the design of a commercial-scale wing derivative in a scale-up task. A high-fidelity finite element (FE) structural model is the first block in the modelling process. A condensed FE model together with aerodynamic models based on the doublet-lattice (DLM) and vortexlattice (VLM) methods represent the aeroelastic system. The aerodynamics represented by the afore-mentioned panel methods is complemented by results from higher-fidelity computational fluid dynamics (CFD) simulations. Reduced-order aeroservoelastic models suitable for control-synthesis are then generated using a "bottom-up" modelling approach. The aim of the paper is to present an overview of the different models encountered during such a design process and their domains of application.
\end{abstract}

\footnotetext{
* Research Scientist, Loads Analysis and Aeroelastic Design

${ }^{\dagger}$ Professor, Department Leader - Loads Analysis and Aeroelastic Design

${ }^{\ddagger}$ Research Scientist, Aircraft Systems Dynamics

$\S$ Research Associate, Institute of Aircraft Design

IProfessor, Head - Institute of Aircraft Design

"Research Associate, Chair of Aerodynamics and Fluid Mechanics

**Professor, Head - Chair of Aerodynamics and Fluid Mechanics

${ }^{\dagger \dagger}$ Research Engineer

$¥$ Research Fellow, Computer and Automation Research Institute

$\S \S$ Senior Research Fellow, Systems and Control Lab
} 


\section{Introduction}

The Flutter-Free Flight Envelope Extension for Economical Performance Improvement or FLEXof 1 is a European research project aiming to develop and demonstrate technological concepts to improve performance of flexible, high-aspect ratio, swept aircraft wings. In particular, active flutter control and load alleviation through aeroelastic tailoring will be demonstrated on an unmanned flying aircraft. ${ }^{2[9}$

The design and testing of new technologies on a commercial-scale aircraft is usually cost-prohibitive. The rationale is that by using a smaller unmanned aerial vehicle (UAV) as a test-platform, new technologies can be tested within a complete aircraft design exercise, at a comparatively lower cost. The methods and concepts developed can then be applied to the design of the actual full-scale aircraft in a scale-up task. Within FleXOP, the scale-up task involves designing a derivative of an existing wing (the Airbus XRF1), having an increased span, a higher aspect ratio and more structural flexibility.

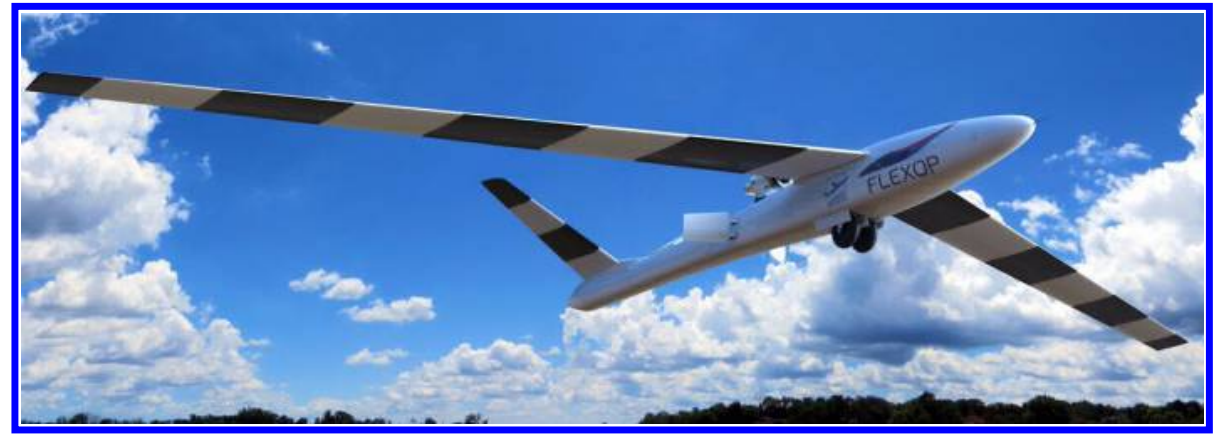

Figure 1. FLEXOP demonstrator aircraft

In total, three pairs of wings are planned to be manufactured and tested on the UAV test-bench:

i) wings -0 - a pair of wings 890 optimized using balanced-symmetric type of laminates serving as the reference wing

ii) wings -1 - a pair of flutter wings 3 [5 designed to trigger flutter within the test-regime, whose flight envelope will then be extended using active flutter control

iii) wings - 2 - a pair of wings $\$ \sqrt[8]{9}$ optimized using unbalanced composite laminates, to demonstrate passive load alleviation through aeroelastic tailoring

The high aspect ratio and flexible nature of the wings necessitate an accurate modelling of the flexible aircraft in order to represent its aeroelastic behavior. The models discussed in this paper are aeroservoelastic models, which are based on an integration of the following disciplines - aerodynamics, structural dynamics, flight dynamics and the servo/actuator dynamics. Models for each of these disciplines are developed separately and combined to form the aeroservoelastic model. The structural dynamics model is obtained from a detailed Msc.NASTRAn finite element (FE) model. The FE model is updated based on results from a static test and a ground vibration test (GVT) campaign. A flexible aeroelastic model is then set-up. The aerodynamics is modeled using the vortex lattice method (VLM) for steady and doublet lattice method (DLM) for unsteady cases, with the provision to improve the fidelity of the aerodynamics computation using computational fluid dynamics (CFD) methods. Dynamic models for flight systems such as engines, for external disturbances, for sensors and actuators are added to form the full-order non-linear aeroservoelastic model. The non-linear system is linearized at several trim points and their state-space representations are obtained. A reduced-order, linear parameter-varying (LPV) model is set up using a bottom-up modelling approach for the control design step. The modelling toolchain is summarized in Figure 2.

This paper aims to present the modelling workflow that was developed and applied during the course of the FlEXoP project. This modelling toolchain has been divided into four main blocks, judged by their core disciplines:

- aircraft level structural model and its update

- flexible aeroservoelastic model

- CFD methods for improved aerodynamics

- reduced-order model for control synthesis 


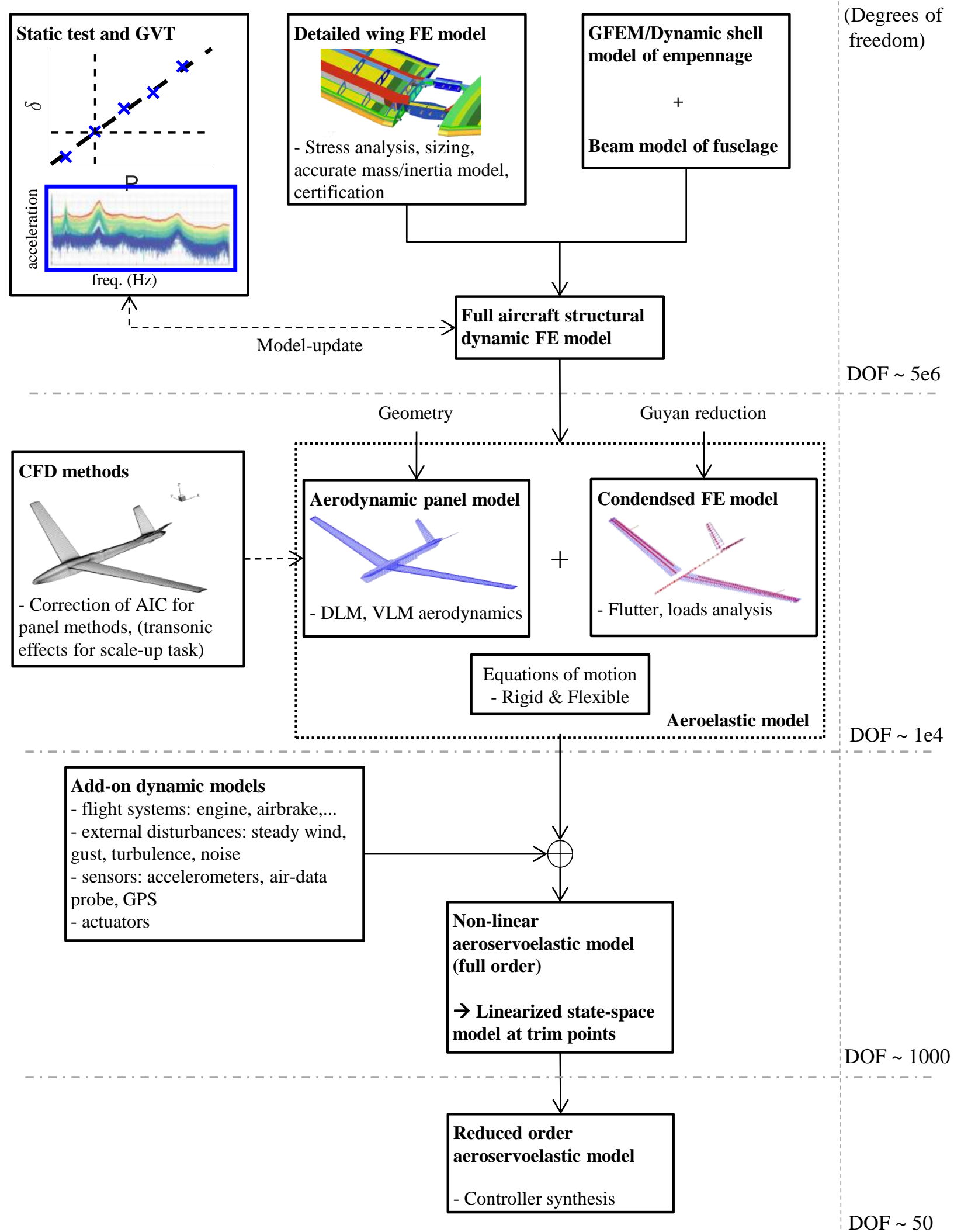

$\mathrm{DOF} \sim 50$

Figure 2. Modelling workflow within the FLEXOP project 
In each of the following sections, the modelling process pertaining to the blocks mentioned is elaborated. For the purpose of this paper, the flutter wing (-1) has been chosen as an example except in the modelupdating part which has up to the point of writing, been performed for the reference wing $(-0)$.

The present paper focuses on the aeroservoelastic modeling aspects within the FLEXOP project and has been presented together with papers on the design 10 and controller development 11 of the FLEXOP UAV, and along with work $\frac{12}{14}$ on the Performance Adaptive Aeroelastic Wing (PAAW) project in a joint FLeXoPPAAW session.

\section{Aircraft-Level Structural Model}

\section{A. Wing structural model - Flutter wing (-1)}

The structural wing design for the flutter wing (-1) is developed to exhibit a pre-defined flutter characteristic. To ensure an affordable solution, the design has to feature a sufficiently low flutter velocity, as well as flutter frequency.

The design is based on a twin-spar concept in combination with a sandwich wing shell. To reach the main desired aeroelastic characteristic, the adjustment of the wing stiffness is one of the main driving structural design criteria. As the wing has to be relatively flexible to ensure onset of flutter within the flight envelope, glass fiber reinforced plastic (GFRP) is used due to its lower material stiffness. To prevent local elastic instabilities while keeping the overall wing stiffness soft, a foam core is used to increase the local bending stiffness and therefore, the resistance against buckling. To resist the concentrated forces around the wing root and wing-fuselage interface, the wing shell sandwich structure is replaced by a monolithic lay-up in this region. The torsional stiffness of the wing is mainly provided by the wing shell and consists of $\pm 45^{\circ}$ plies. The lift and respectively, the bending moment are mainly carried by the spar caps which are made of carbon fiber reinforced plastic (CFRP) composites. There is also a provision to place an additional mass aft of the wing via a cylindrical device. The set-up allows the mass to be positioned at different locations in the chord-axis such that the flutter behaviour of the wing can be tuned.

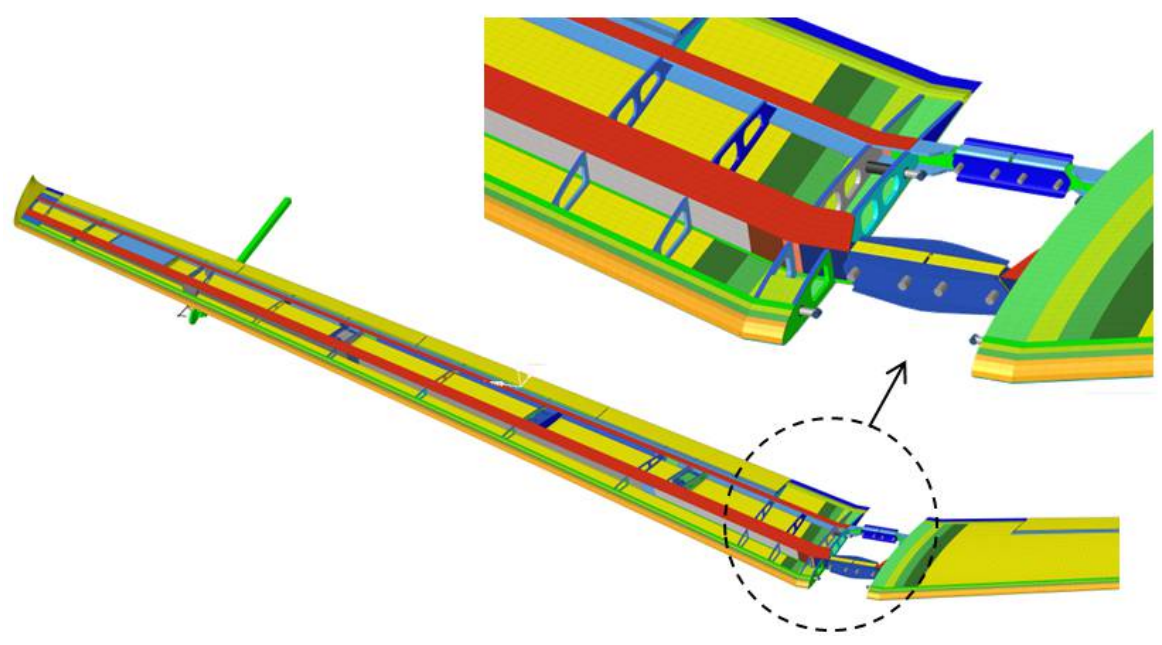

Figure 3. FE model of the flutter-wing (-1)

The main spar is located at $26 \%$ and the rear spar at $70 \%$ of the root chord. In total, the wing has 20 ribs to support the skin. The ribs are further used as servo and flap attachment points. Together with the front and rear spar, a closed wing-box is realized and used as the main load-carrying structural element.

As the stiffness and mass distributions have a major impact on the flutter behavior of the wing, a highly detailed structural modeling approach is applied. Wing skin, spar, and ribs are treated as thinwalled structures and therefore discretized with linear shell elements. Each structural part is set up as a single component and is connected in an additional assembly process to the wing. The single-part approach holds the advantage that deviations caused by shell offsets can be reduced. A detailed model of the four control surfaces and their kinematics is also present. To have a highly accurate prediction of the mass 
distribution, the connection parts like glue, bearings and metallic joints are realized with solid, beam and rigid interpolation elements. Components like cables or sensors are represented as discrete mass elements.

\section{B. Fuselage and empennage models}

The fuselage hull is represented as an equivalent beam using a cross-sectional modeler ${ }^{[15}$ Based on a geometry and composite layup definition for each line element describing the (multi-cell) cross-section, the modeler computes a full Timoshenko stiffness matrix and a mass matrix including shear and mass center. The stiffness and mass matrices are then used to define the beam elements in MsC.NASTRAN. A beam model is chosen for the fuselage since it is sufficient to represent its structural dynamic behaviour - its first natural frequencies are much higher than the that of the wing and the critical aircraft flutter modes have very little contribution from the fuselage.
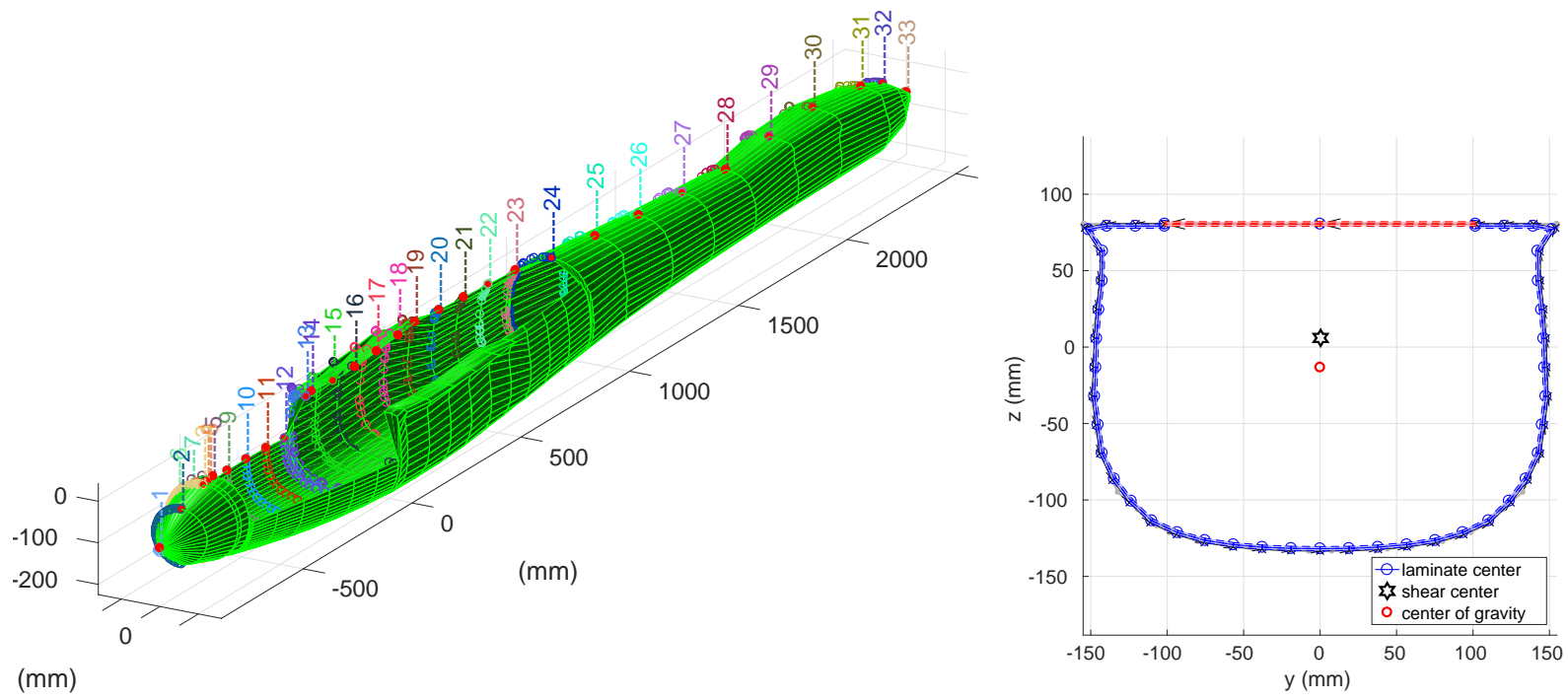

Figure 4. Cross-sectional cuts of fuselage used for generating the equivalent beam model (left), example of a cross-sectional cut at Section-15 (right)

In this modelling approach, the stiffness contributed by the fuselage hull is considered, while the internal structure - bulkheads, stiffeners, local reinforcements at mounting points etc. - are not included. However, their mass and inertia are accounted for, so that the dynamic behavior of the fuselage is well characterized. Figure 4 shows the fuselage hull and the constituent cross-sectional-cuts making up the nodes of the beam model. Additional system masses and their inertia are also modeled as point masses. The wing attachment is provisioned through four points, imitating the four elastically mounted shear bolts. Spring elements are provisioned at these attachment points to account for any softness in the attachment, which will then be tuned for using results from the dynamic identification of the aircraft (GVTs).

The structural model of the $\mathrm{V}$-tail empennage is represented by a shell-element based FE model, generated using the modeling tool ModGEN ${ }^{16}$. The model comprises of shell-element representations of the primary load-carrying components - upper, lower skins, ribs and spars. Concentrated masses and inertia are used for the non-structural components such as the various systems. The empennage is connected to the fuselage via four connection points. The elevators in the empennage are accounted for only as additional lifting surfaces in the aerodynamic panel model and are not included in the FE model.

\section{Static Guyan reduction}

The structural FE model of the full UAV is obtained by assembling the models of the fuselage, wings and empennage. In the case of the flutter wing $(-1)$ for instance, a detailed FE model $(\sim 600,000$ grid points) is necessary to calculate the local strains needed for sizing and for a very accurate representation of the structural dynamics - the mass and inertia. 
In order to reduce the number of degrees of freedom in the model, a static reduction or Guyan reduction 17 is performed. For the wings, 222 points in total are chosen for the condensation, equally distributed in the main wing-box and in the flaps. For the empennage, condensation nodes are placed at the rib-locations, while for the fuselage, the fuselage beam nodes are selected. Condensation points are also placed at useful force-introduction points such as the engine thrust point, the air-brake point and at the different flutter tuning-mass locations. Shown in Figure 5 is the assembled full FE model of the flutter-wing (-1) configuration of the UAV together with the condensation points used for the Guyan reduction.

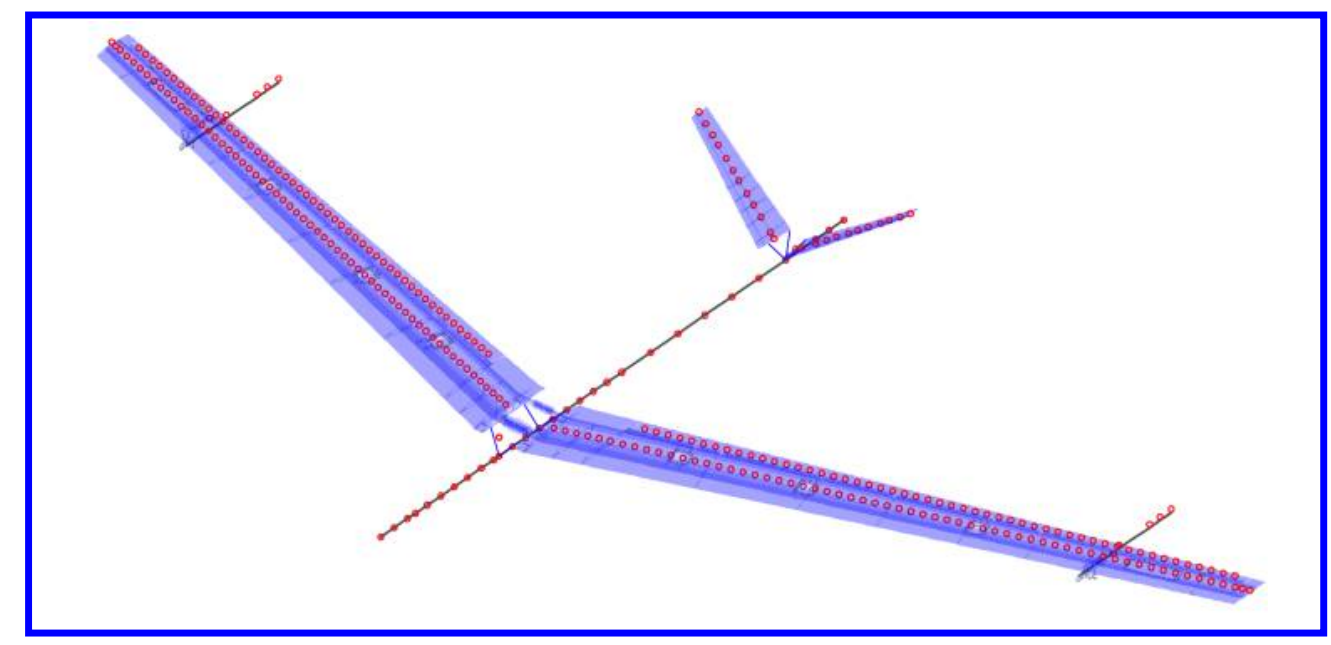

Figure 5. FE model of the flutter wing (-1) aircraft and the nodes used for the Guyan condensation (denoted as red dots)

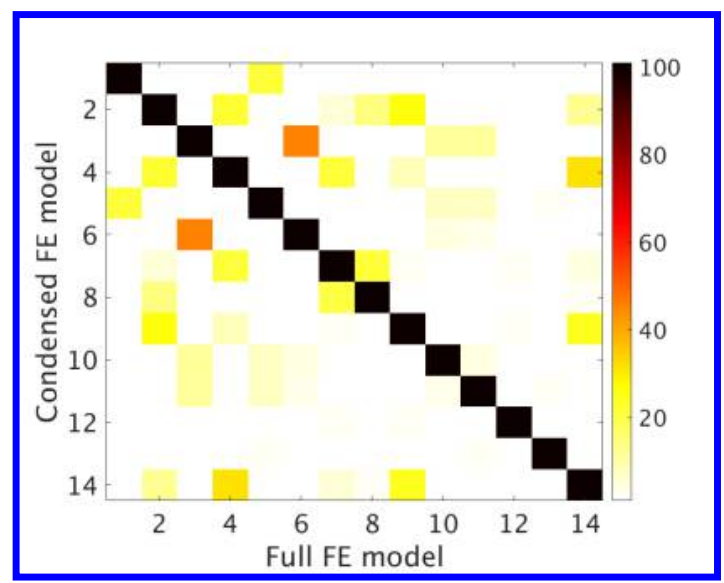

Figure 6. MAC matrix showing the correlation of modes between the full FE model and the condensed model (Note: only the flexible modes are denoted in this figure)

As long as the forces in the full model are introduced only at these set of condensed nodes, the condensed model possesses an exact solution to any static problem. For the purpose of the aeroelastic analysis, this is ensured by splining the aerodynamic forces only onto these nodes from the structural model. The static reduction however, does not preserve the mass matrix in the same way that the stiffness matrix is preserved. A check of the modal assurance criterion or the MAC matrix, between the full and the condensed model, in Figure 6, shows that the flexible modes in the region of interest are captured in the condensed model, thus sufficiently preserving the structural dynamics behavior of the full model. 


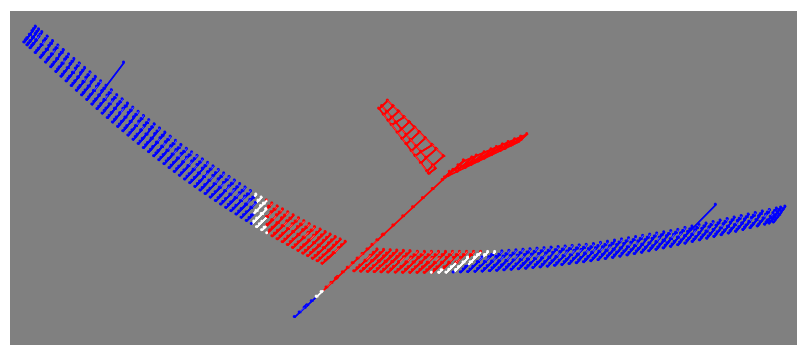

(a) $1^{\text {st }}$ wing bending (symmetric) $=2.91 \mathrm{~Hz}$

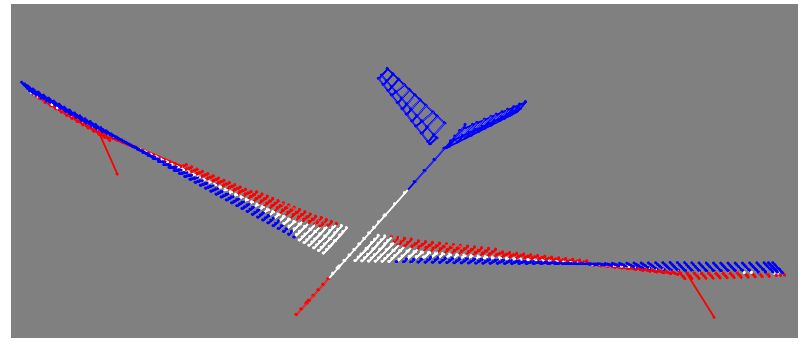

(c) $1^{\text {st }}$ wing torsion $($ symmetric) $=10.50 \mathrm{~Hz}$

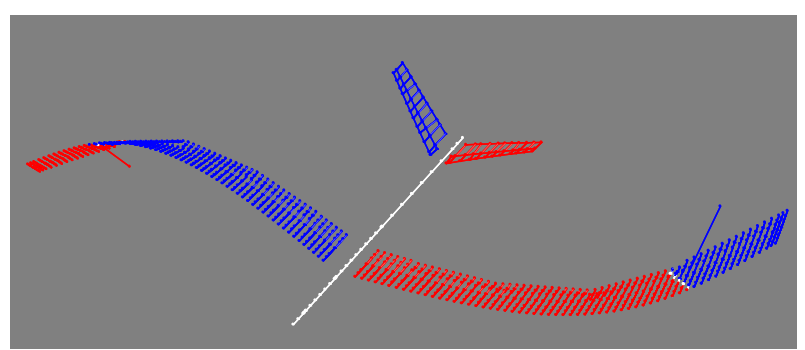

(b) $1^{\text {st }}$ wing bending (anti-symmetric) $=8.15 \mathrm{~Hz}$

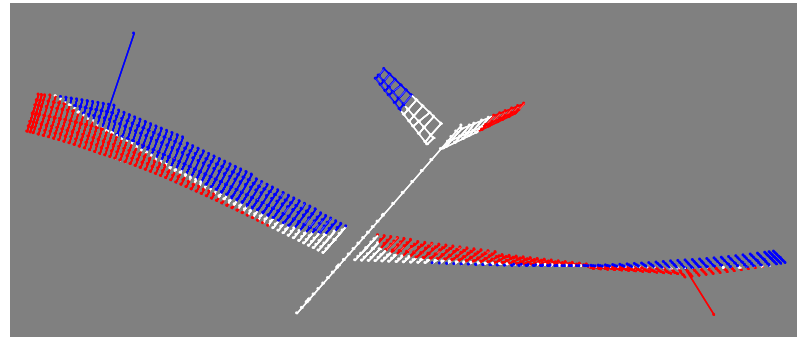

(d) $1^{\text {st }}$ wing torsion (anti-symmetric) $=10.60 H z$

Figure 7. First 4 eigen-modes of the flutter wing (-1) aircraft from the condensed FE model

\section{Structural Model Update}

A structural model-updating step is performed in order to improve the accuracy of the FE model used in an initial design process, to match the structural behavior of the manufactured part or component obtained using experiments. This difference between the FE model and the experiments can arise due to modelling accuracies, material scatter, manufacturing deviations, etc. The model-updating step becomes more so critical in cases where the responses are very sensitive to change in static or dynamic properties as is in the case of aeroelastic flutter, and when these updated models need to be fed back into a design process, for instance in a controller design step.

The structural model-updating in this case is performed using two sets of experiments - i) deformations measured using static tests will be used to update the stiffness of the FE model, ii) modes shapes and eigen frequencies obtained from a GVT will be used to tune the mass properties of the FE model. In this paper, the static tests and the model-update method applied for the reference wing (-0) are described. A similar test and update routine will also be performed for the flutter wing $(-1)$ in the future, along with the GVTs.

\section{A. Static test and model update}

For the static test, both wing-halves are mounted onto a test-stand with similar attachment and support conditions as in the flying UAV. Symmetric loads are then applied according to a pre-defined test matrix and the deformation is measured using a laser-based tracker at several points along the wing-span and chord.

In a first quick approach for the model-updating, an artificial "tuning" beam is added to the FE model. The tuning beam is discretized with each element defined between two ribs, where the beam nodes are connected with their respective ribs through interpolation elements as shown in Figure $8 \mathrm{a}$. The convenience of this approach is that these interpolation elements are already required and present for the static condensation step. By varying the stiffness of the tuning beam elements, the effective stiffness of the entire wing structure can be adjusted. In the case of the reference wing (-0), 26 beam elements are defined between the 27 ribs. These beam elements are then grouped into five unique beam properties.

An optimization problem is set up within Msc.NASTRAN. The objective of the optimization is to minimize the difference in the deformation between the experimental measurement points and the FE model, at selected control points for one load case. The design variables are the stiffness terms of the beam elements (CBEAM in Msc.Nastran). A comparison of the deformation between the experimental results, the initial FE model and the updated FE model for two different load magnitudes is shown Figure $8 \mathrm{p}$. 


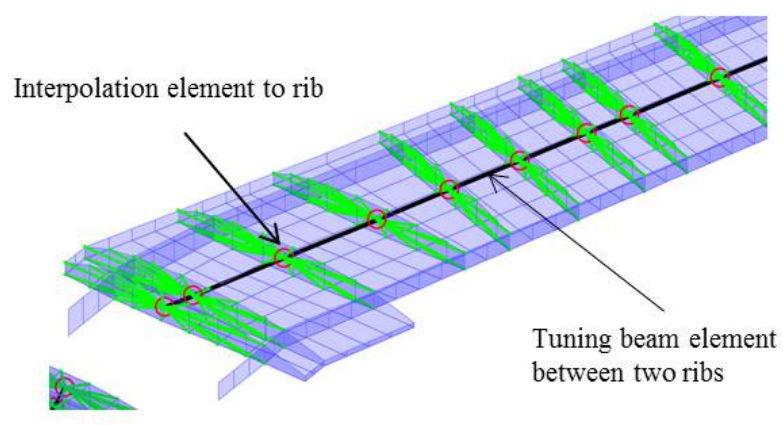

(a) FE model of reference wing (-0) with the tuning beam

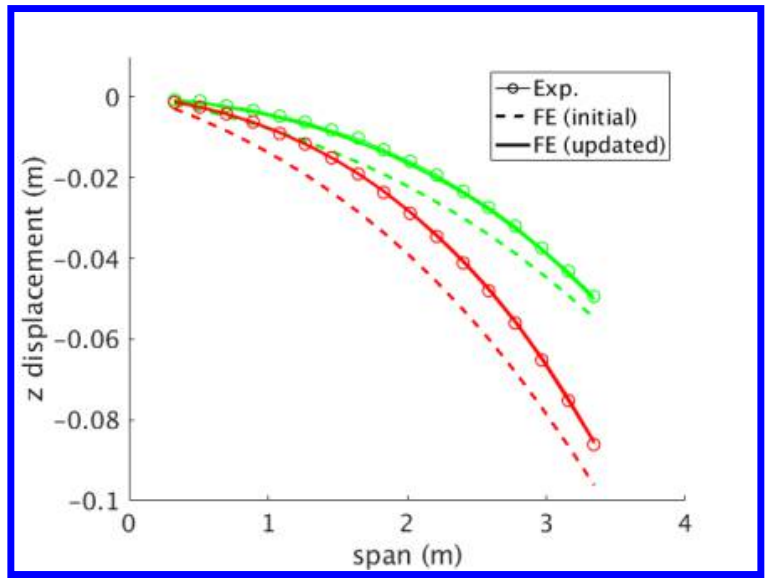

(b) Displacements from static test under two different loads: experimental results vs initial FE model vs updated FE model

Figure 8. FE model stiffness update for the reference wing (-0)

An alternative method of updating the stiffness by directly using physical quantities in the model such as the material stiffness, ply angles, etc. as design variables in this optimization problem will be studied in the next future steps. The results obtained would then carry better physical insight; however care must be taken to ensure that the limits within which these physical properties can vary remain sensible.

\section{B. Ground vibration tests}

Having updated the stiffness properties of the numerical models using the static test results, GVTs will be performed next to characterize the dynamic behavior of the manufactured wings.

In the case of the GVTs, the full UAV will be instrumented with accelerometers, suspended on an elastic string and excited with an impulse hammer. From the time-response of the accelerometers, a modal analysis will be performed to obtain the eigen frequencies, mode shapes and damping corresponding to each of the modes. The results will then be used to update the FE models of the full UAV aircraft, either by using "tuning" or "artificial" beam elements via their mass properties or by varying the density parameters in the FE model.

\section{Flexible Aeroservoelastic Model}

\section{Aerodynamic panel model}

The steady and unsteady aerodynamics in the aeroservoelastic model is accounted for using panel methods - VLM and DLM respectively. The aerodynamic model of the aircraft, shown in Figure 9, is obtained by discretizing the lifting surfaces - wing, fuselage and empennage - into several trapezoidal panels. For the fuselage, a T-cruciform shaped panel arrangement is used, by projecting the wetted area of the fuselage. This panel model serves as a place-holder for correction of the fuselage aerodynamics, which in this case is done using CFD simulations. The aerodynamic panel model is extended with an estimation for the drag based on a drag polar.

\section{Aero-structure coupling}

The coupling between the structural deformation in the condensed FE model and aerodynamic forces in the panel model is facilitated via a spline model as shown in Figure 9. For the fuselage, the beam nodes are used for the splining. For the empennage, each condensation node is extended toward the leading and trailing edge using rigid elements and these three-noded arrangements are used for the splining. Such an arrangement offers a smooth splining by ensuring that the spline nodes cover the entire aerodynamic surface. A similar arrangement is made for the wing, except that the control surfaces possess their own three-noded 


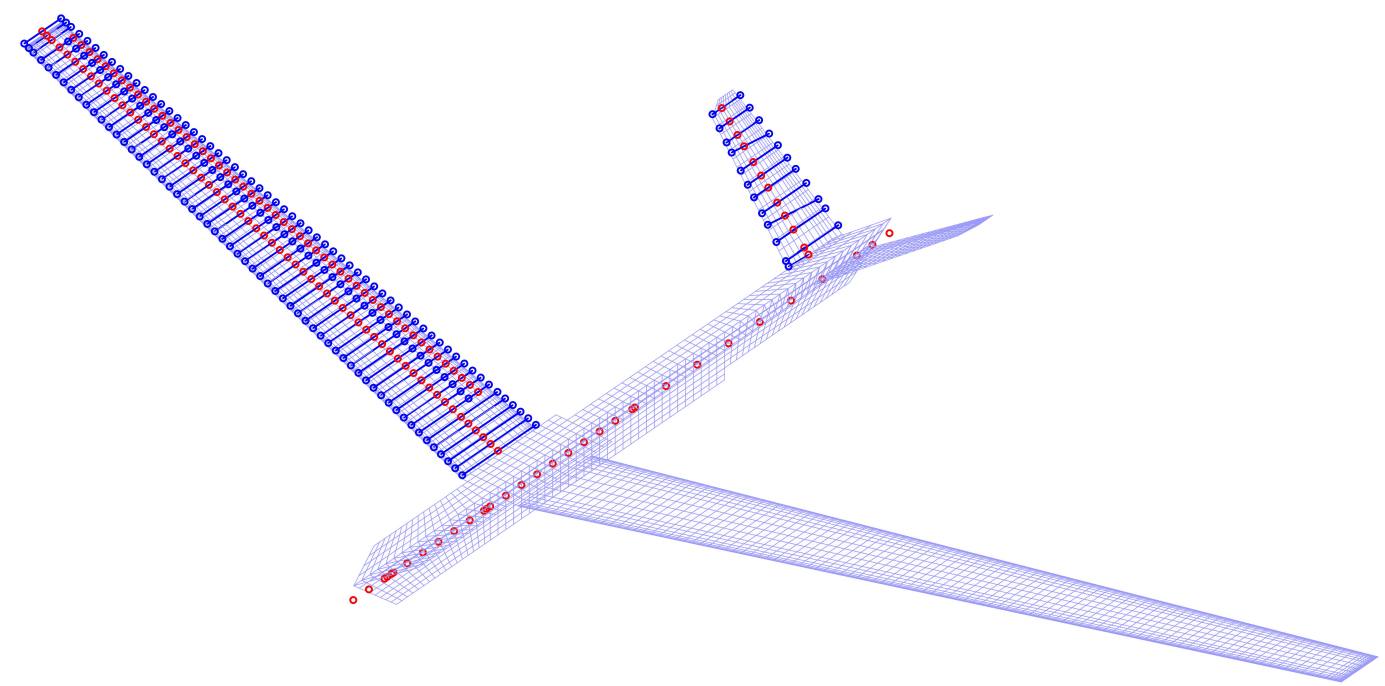

Figure 9. Aeroelastic model of the (-1) full aircraft - aerodynamic panels and aero-structure splining nodes shown for right half of aircraft (splining nodes which are condensation points shown in red)

arrangements. The aerodynamic forces generated due to a control surface deflection are thus introduced only onto the respective structural nodes of the control surface. The structural FE model and aerodynamic model coupled via the spline model represents the full aeroelastic model of the aircraft.

\section{Aeroservoelastic model}

The equations of the aeroelastic model can be divided into a rigid and a flexible motion. The rigid body motion of the aircraft is described by

$$
\left[\begin{array}{c}
m_{b}\left(\dot{V}_{b}+\Omega_{b} \times V_{b}-T_{b e} g_{e}\right) \\
J_{b} \dot{\Omega}_{b}+\Omega_{b} \times\left(J_{b} \Omega_{b}\right)
\end{array}\right]=\Phi_{g b}^{T} P_{g}^{\operatorname{ext}}(t),
$$

where the $m_{b}$ and $J_{b}$ are the mass and mass moment of inertia. $\frac{18}{18}$ The translational and angular velocity of the aircraft with respect to the body frame of reference are given by $V_{b}$ and $\Omega_{b}$. The vector $T_{b e} g_{e}$ represents the gravitational acceleration transformed to the body fixed frame of reference. On the right hand side of the equation the external loads $\Phi_{g b}^{T} P_{g}^{\text {ext }}(t)$ acting on the aircraft structure are summed up 18$] 19$

By means of the linear elastic theory the correlation between external loads $P_{g}^{\text {ext }}(t)$ and the generalized coordinates $u_{f}$ representing the modal deformation of the structure is given by the differential equation

$$
M_{f f} \ddot{u}_{f}+B_{f f} \dot{u}_{f}+K_{f f} u_{f}=\Phi_{g f}^{T} P_{g}^{\mathrm{ext}}(t),
$$

where $M_{f f}, B_{f f}$ and $K_{f f}$ are the modal mass, damping and stiffness matrices respectively. The modal matrix $\Phi_{g f}$ contains the eigenvectors of the structural modes sorted by frequency 19

By adding the aerodynamic forces to the external forces, the correlation between the aerodynamic and the structural model is established, like shown in Figure 10. The VLM or DLM provide the corresponding pressure coefficients $\Delta c_{p j}$, which can be determined by

$$
\Delta c_{p j}=Q_{j j} w_{j} .
$$

The matrix $Q_{j j}$ represents aerodynamic influence coefficients. It is multiplied with $w_{j}$, which is the downwash $v_{j}$ normalized with the flight speed $U_{\infty}$. More information on the aerodynamic modeling is provided in Wuestenhagen et al $\stackrel{5}{[5}$ Based on the pressure coefficients the aerodynamic forces are given by

$$
P_{g}^{\text {aero }}=q_{\infty} T_{k g}^{T} S_{k j} \Delta c_{p j} .
$$

The integration matrix $S_{k j}$ relates the pressure coefficients in the aerodynamic boxes with the aerodynamic forces. The forces at the aerodynamic grid points are interpolated onto the structural grid points with the 
transpose of the spline matrix $T_{k g}$. Multiplying with the dynamic pressure $q_{\infty}$ leads then to the aerodynamic loads $\sqrt{19 \sqrt{20}}$

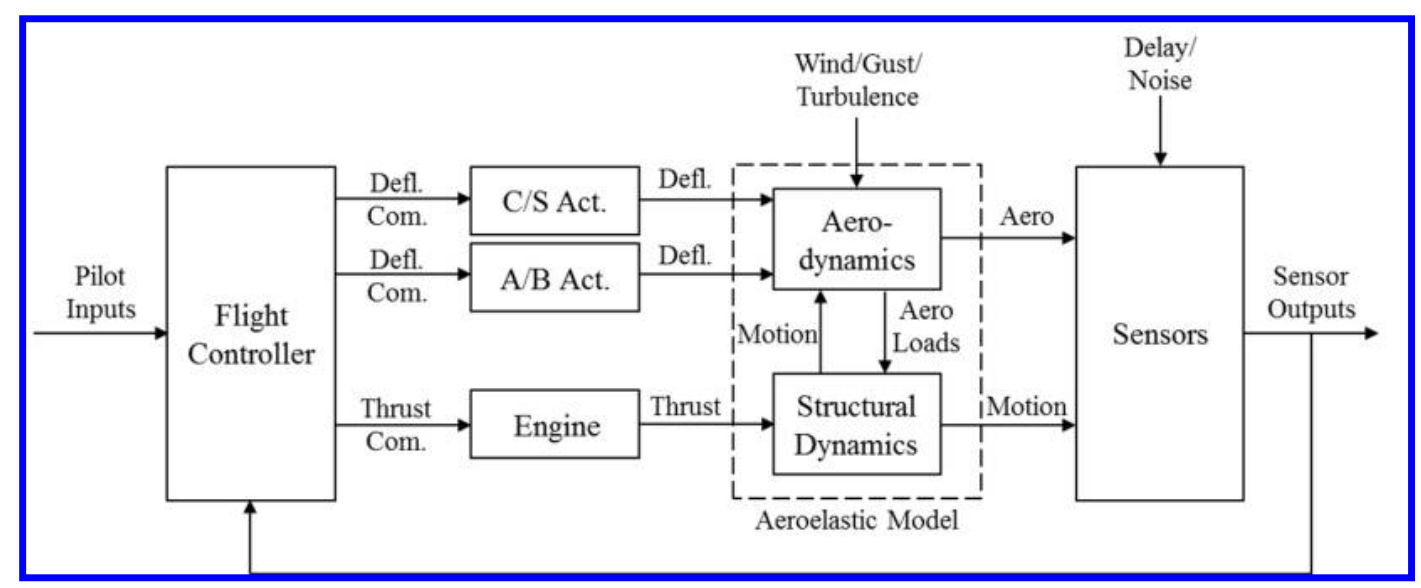

Figure 10. Structure of the FLEXOP aeroservoelastic model

Subsequently, additional features are included in the model as schematized in Figure 10 . The engine thrust acts on the aircraft structure, while the deflections of the control surface actuators and airbrake actuators directly affect the aerodynamics. Additionally environmental conditions like steady wind, gusts and turbulences change the aerodynamic characteristics of the aircraft. Various sensors detect the aircraft dynamics and flight conditions within the entire mission. The readings of the inertial measurement unit (IMU) sensors, installed in the wings and the fuselage, help to distinguish between rigid body motion and flexible deflection of the aircraft structure. Air-data sensors detect parameters like the barometric height, the indicated airspeed and the angle of attack. A GPS unit provides the position of the aircraft. Sensor delays and noise extend the sensor models. The onboard sensor measurements are the outputs, while the pilot commands like the control surface and airbrakes deflections and the thrust are the inputs to the system.

The representation of the aircraft dynamics is non-linear. Linearization allows determining state-space systems of the form

$$
\begin{aligned}
\dot{x}(t) & =A x(t)+B u(t) \\
y(t) & =C x(t)+D u(t) .
\end{aligned}
$$

The first equation describes the physics of the underlying system and correlates the inputs $u(t)$ and the states $x(t)$ with respect to time. The second equation provides the sensor outputs $y(t)$ with respect to the inputs and states. Based on these equations, control laws for the baseline and the flutter controller can be derived. The sensor outputs serve as inputs to the controller, which determines the necessary control commands to the engine, the control surface and airbrake actuators.

The full-order, non-linear aeroservoelastic model comprises of close to 1600 states including rigid body, flexible mode, aerodynamic lag and actuator dynamics states.

\section{CFD Methods for Improved Aerodynamics}

With an important outcome of the FLEXOP project being its scalability to practical large-scale aircraft, the ability to handle aerodynamic effects such as transonic shocks is important. Toward this end, steady and unsteady CFD methods have been incorporated into the tool-chain.

For the steady CFD simulations, Navier-Stokes computations using the DLR-TAU code are performed for trimmed points at different flight speeds. The VLM does not consider aerodynamic effects due to camber and twist. As the CFD simulations provide more accurate results than the VLM, the results are used to update the steady aerodynamic model. Figure 11 a shows the lift distribution along the left wing for the VLM and the CFD calculation at $45 \mathrm{~m} / \mathrm{s}$ and an angle of attack $0^{\circ}$. The distributions of the lift gradients shown in Figure 11b on the other hand, match very well and an update is therefore not necessary.

For the unsteady CFD simulations, the small-disturbance (SD) Euler solver AER-SDEu, developed at the Chair of Aerodynamics and Fluid Mechanics of the Technical University of Munich is used for the 


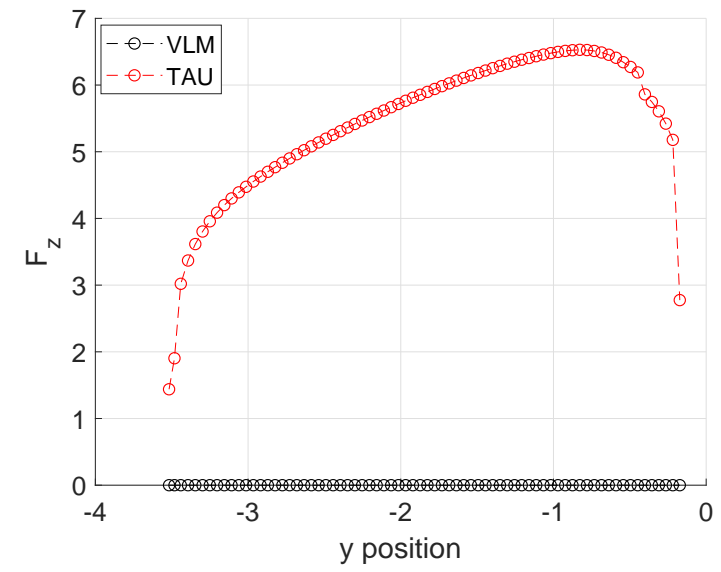

(a) Lift distribution for $\alpha=0^{\circ}$

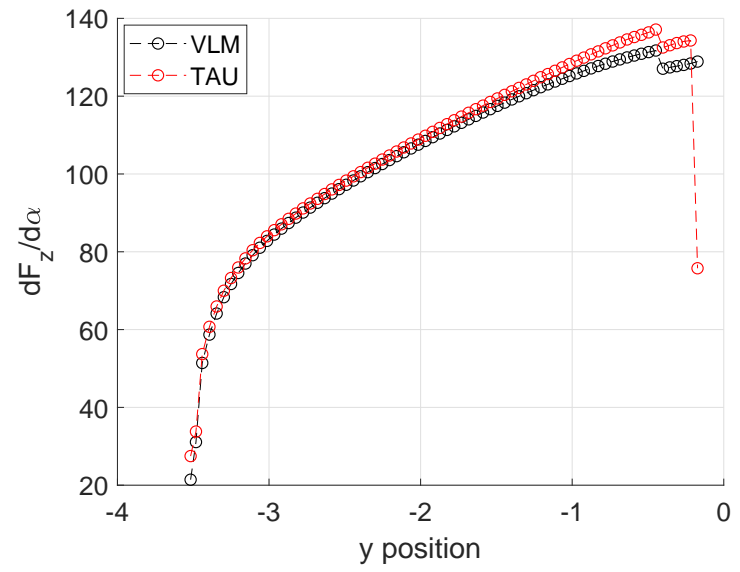

(b) Lift gradient distribution

Figure 11. Comparison of lift and lift gradient distribution between VLM and CFD (DLR-TAU)

computation of the generalized aerodynamic forces (GAFs). AER-SDEu solves the linearized Euler equations in the frequency domain that can be derived from the full set of non-linear Euler equations by assuming small, harmonic oscillations of the flow field around a reference state. Compared to established linear-potentialtheory-based methods, the SD approach provides a better accuracy with regard to complex three-dimensional flows. Moreover, it captures nonlinear compressibility phenomena making it possible to predict the drop of the flutter boundary in the transonic region.

While being more efficient than time-accurate nonlinear CFD, SD-CFD represents a convenient means for the GAF-computation in the transonic region and thus, also for the flutter analysis of modern transport aircraft. AER-SDEu has been integrated in the FLEXOP toolchain and is employed to compute the GAFs and aerodynamic derivatives. The SD-CFD-based results can be used to correct the DLM-based aerodynamic dataset.

A half-model of the FLEXOP demonstrator is used for the SD-CFD analysis. Therefore a structured multi-block mesh is generated employing ANSYS ICEM CFD HEXA. The surface CFD-grid of the model is depicted in Figure 12

The computational domain is discretized with 10.7 million cells. The distance between the half-model and the far-field boundaries is set to approximately 15 semi-spans in all directions. A symmetry boundary condition is set at the plane of symmetry and the wall boundary condition is imposed at the surface of the aircraft geometry. The off-body distance of the first grid line is $0.1 \mathrm{~mm}$ or approximately $0.03 \%$ of the mean aerodynamic chord. The wing is resolved with 113 cells in chordwise and 129 cells in spanwise direction. A simplified actuator fairing is incorporated into the CFD model to investigate its aerodynamic influence on the flutter behavior.

To compute the unsteady aerodynamic loads due to modal excitations of the aircraft, corresponding perturbed CFD grids are provided. The grids are deflected according to the shapes of the structural eigenmodes employing the thin-plate-spline method and the transfinite interpolation. For each modal deflection, a simulation run is performed at each reduced frequency under consideration. Thus, a CFD-based GAF-database is computed for the first 30 structural eigenmodes at 8 reduced frequencies, resulting in 240 simulations.

\section{Reduced-Order Model for Control Synthesis}

The flutter suppression control design is generally based on an appropriate control-oriented model. 21.25 A natural approach for aeroservoelastic (ASE) system modeling is the linear parameter-varying (LPV) $26 \sqrt[27]{27}$

framework, which captures the parameter-varying dynamics of the aircraft. The grid-based LPV framework ${ }^{28}$ is the focus of this paper. A grid-based LPV model can be obtained by linearizing the nonlinear model over 


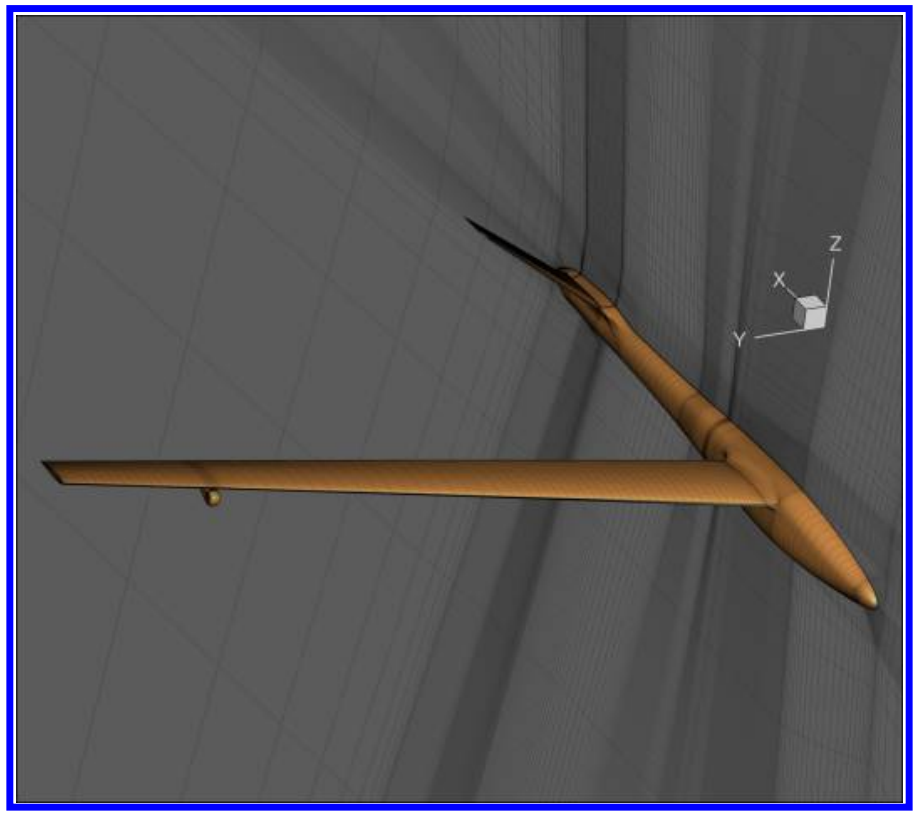

Figure 12. Surface CFD grid for unsteady simulations of the FLEXOP demonstrator

a set of equilibrium points. ${ }^{[2]}$ An LPV system is described by the state-space model,

$$
\begin{aligned}
& \dot{x}(t)=A(\rho(t)) x(t)+B(\rho(t)) u(t) \\
& y(t)=C(\rho(t)) x(t)+D(\rho(t)) u(t)
\end{aligned}
$$

with the continuous matrix functions $A: \mathcal{P} \rightarrow \mathbb{R}^{n_{x} \times n_{x}}, B: \mathcal{P} \rightarrow \mathbb{R}^{n_{x} \times n_{u}}, C: \mathcal{P} \rightarrow \mathbb{R}^{n_{y} \times n_{x}}, D: \mathcal{P} \rightarrow \mathbb{R}^{n_{y} \times n_{u}}$, the state $x: \mathbb{R} \rightarrow \mathbb{R}^{n_{x}}$, input $u: \mathbb{R} \rightarrow \mathbb{R}^{n_{u}}$, output $y: \mathbb{R} \rightarrow \mathbb{R}^{n_{y}}$ and a time-varying scheduling signal $\rho: \mathbb{R} \rightarrow \mathcal{P}$, where $\mathcal{P}$ is a compact subset of $\mathbb{R}^{n_{\rho}}$. The parameter vector $\rho$ may include elements of the state vector $x$, in which case the system belongs to the class of quasi-LPV models. In a grid representation, the LPV system is described as a collection of LTI models $\left(A_{k}, B_{k}, C_{k}, D_{k}\right)=\left(A\left(\rho_{k}\right), B\left(\rho_{k}\right), C\left(\rho_{k}\right), D\left(\rho_{k}\right)\right)$ obtained by evaluating the LPV model at a finite number of parameter values $\left\{\rho_{k}\right\}_{1}^{n_{\text {grid }}}=\mathcal{P}_{\text {grid }} \subset \mathcal{P}$.

The nonlinear ASE model of the FLEXOP aircraft consists of 12 rigid body states, 100 flexible mode states and 1040 aerodynamic lag states in addition to the actuator dynamics. Control design for such a high-dimensional LPV (or even LTI) model is not possible. Therefore, the model needs to be reduced. LPV model order reduction is still not a completely straightforward task $\frac{30}{36}$ The goal is to overcome the LPV reduction step by applying a "bottom-up" modeling approach ${ }^{37}$ The key idea is the following. The structural dynamics and aerodynamics subsystems have a simpler structure than the combined ASE model. Thus, the order of these subsystems can be reduced by simpler and more tractable reduction techniques. Such an approach leads to a reduced-order nonlinear ASE model that is of sufficiently low order for LPV(or LTI-) based control design.

It is crucial to define a frequency range of interest in which it is expected that the reduced-order ASE model is a good approximation of the full-order ASE model. Since the main goal of the control design is flutter suppression, the flutter frequency $(50.2 \mathrm{rad} / \mathrm{s}$ and $45.8 \mathrm{rad} / \mathrm{s})$ determines the frequency range for which an accurate model is required. At frequencies higher than $100 \mathrm{rad} / \mathrm{s}$ the controller is expected to roll off. Therefore, the frequency range of interest for the reduced-order model is defined up to $100 \mathrm{rad} / \mathrm{s}$.

\section{A. Bottom-up modeling steps}

Bottom-up modeling of ASE systems is an iterative process. At each subsystem reduction step, it has to be verified if the resulting reduced-order model is accurate enough. As a measure of accuracy, the $\nu$-gap metric $\delta_{\nu}(\cdot, \cdot)$ is used since it takes into account the feedback control objective. It takes values between zero and one, where zero is attained for two identical systems. A system $P_{1}$ that is within a distance $\epsilon$ of another system $P_{2}$ in the $\nu$-gap metric, i. e. $\delta_{\nu}\left(P_{1}, P_{2}\right)<\epsilon$, will be stabilized by any feedback controller that stabilizes 
$P_{2}$ with a stability margin of at least $\epsilon \stackrel{38}{ }$ A plant at a distance greater than $\epsilon$ from the $P_{2}$ on the other hand, will in general not be stabilized by the same controller. The $\nu$-gap metric thus captures the likelihood that a feedback controller designed on the reduced-order model will perform well on the full-order model. It can be calculated frequency by frequency as

$$
\delta_{\nu}\left(P_{1}(\mathrm{j} \omega), P_{2}(\mathrm{j} \omega)\right)=\left\|\left(I+P_{2}(\mathrm{j} \omega) P_{2}^{*}(\mathrm{j} \omega)\right)^{-1 / 2}\left(P_{1}(\mathrm{j} \omega)-P_{2}(\mathrm{j} \omega)\right)\left(I+P_{1}^{*}(\mathrm{j} \omega) P_{1}(\mathrm{j} \omega)\right)^{-1 / 2}\right\|_{\infty}
$$

The $\nu$-gap metric is an LTI technique and the goal is to evaluate it at each LPV grid point. The grid-based LPV model of the FLEXOP aircraft is derived in the following way. The aircraft is first trimmed for straight and level flights at various airspeeds after which the linearization is carried out. Therefore, the scheduling parameter is defined as $\rho=V_{s}$ in the interval $[30,65] \mathrm{m} / \mathrm{s}$ over a grid of 71 equidistant points. The full-order model (FOM) contains the full-order subsystems and the reduced-order model (ROM) contains the reduced subsystems. Since the ROM is aimed for flutter suppression control design, the $\nu$-gap metric is investigated for $L 4, R 4$ inputs, vertical acceleration $\left(a_{z}\right)$ and pitch rate $(q)$ measurements at the C.G. and at the 12 IMUs.

The bottom-up ASE modeling consists of the following three steps.

\section{Step 1: Reduction of the structural dynamics model}

The structural dynamics model is an LTI system. Therefore, its reduction is straightforward and state truncation can be applied. The states to be truncated are selected based on the following considerations. First, the modes that are within the frequency range of interest are retained and the remaining modes are truncated. This results in a reduced-order structural model containing the 6 lowest frequency modes. However, investigating the $\nu$-gap metric for such a ROM and the FOM shows that $\nu$-gap values higher than 0.3 are reached within the frequency range of interest. Such values indicate that the ROM is not accurate enough. Secondly, it is checked whether keeping any additional modes is able to decrease the $\nu$-gap values significantly. Figure 13 shows the maximal $\nu$-gap values for ROMs generated with a reduced-order structural dynamics model that has various modes retained. It can be seen that even retaining the first 18 modes leads to high $\nu$-gap values. If modes 19, 20 and 21 are kept in addition to the first 6 modes, the $\nu$-gap value decreases to acceptable levels. Retaining the first 22 modes further improves the $\nu$-gap values, but at the cost of a large structural dynamics model. Therefore, an acceptable trade-off between size and accuracy of the reduced structural dynamics model is retaining the first 6 modes and modes 19, 20 and 21 . This way the reduced-order structural dynamics model comprises of 18 states as opposed to 100 states of the full-order structural dynamics model.

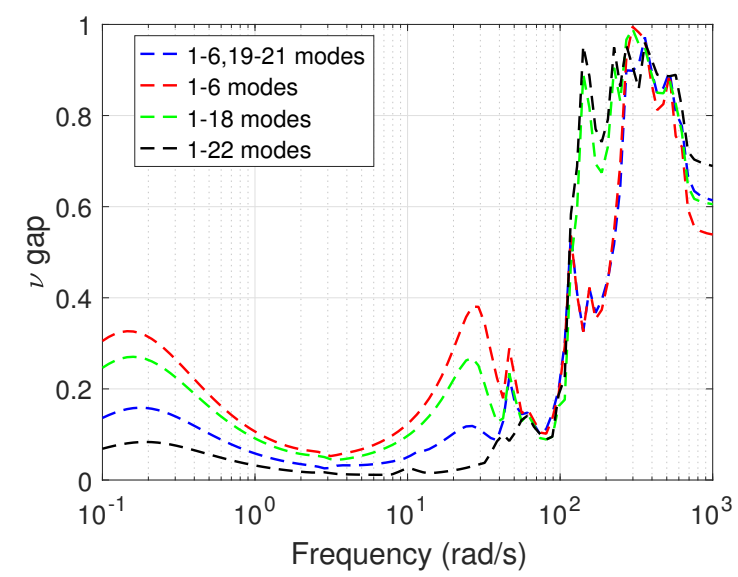

Figure 13. Maximal $\nu$-gap values resulting from structural dynamics model reduction 
Step 2: Selection of poles for the rational function approximation of the DLM aerodynamics

The aerodynamic lag terms can be given in the following state-space form

$$
\begin{aligned}
& \dot{x}_{\text {aero }}=\frac{2 V}{\bar{c}} A_{\text {lag }} x_{\text {aero }}+B_{\text {lag }}\left[\begin{array}{lll}
\dot{x}_{\text {rigid }} & \dot{\eta} & \dot{u}
\end{array}\right]^{T} \\
& y_{\text {aero }}=C_{\text {lag }} x_{\text {aero }}
\end{aligned}
$$

The rational functional approximation (RFA) for the FOM is applied to the physical AIC matrices rather than their fully generalized form. This approach allows a clear separation of steady and unsteady aerodynamic effects which is beneficial for gust load analysis. Such an approach results in a high number of lag states which is disadvantageous for a control oriented model. In the bottom-up modeling approach, the RFA is therefore applied to the generalized AIC matrices. In this case, the number of the resulting lag states is given by

$$
n_{x_{\text {aero }}}=n_{\text {lag } \text { poles }} \times\left(n_{\text {rigid }}+n_{\eta}+n_{\text {input }}\right)
$$

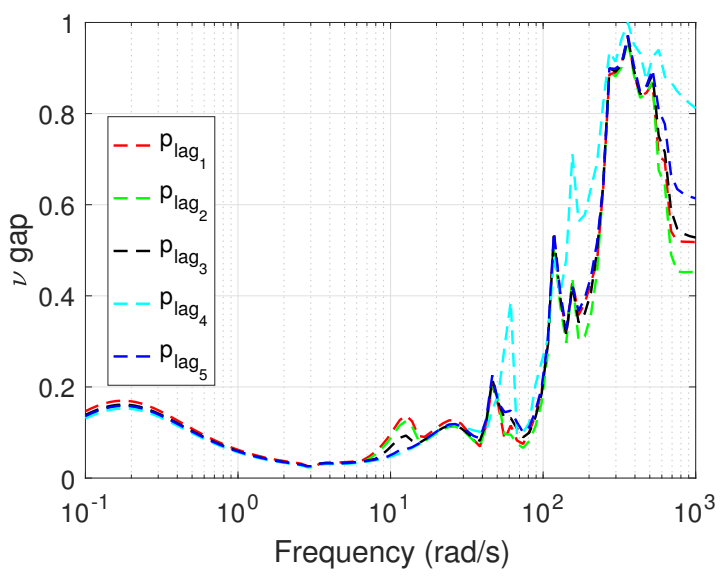

Figure 14. Maximal $\nu$-gap values of the RFA pole selection

The 8 poles of the RFA of the full-order ASE model are the following: $p_{\text {lag }}=[.5, .5714, .6667, .8,1,1.333,2,4]$. In case the structural modes are not reduced, this approach results in an aerodynamic model with 544 lag states. However, the reduced-order structural dynamics model contains only 9 modes, which reduces the number of lag states to 216. In this step, it is investigated how the selection of the poles of the lag state aerodynamics influences the $\nu$-gap metric of the resulting ROM and FOM. Five cases are investigated with the following poles: $p_{\text {lag }_{1}}=[.5, .5714], p_{\text {lag }_{2}}=[.5, .8,2], p_{\text {lag }_{3}}=[.5, .6667,1,2], p_{\text {lag }_{4}}=[.5, .5714, .6667, .8,1,1.333,2,4]$ and $p_{\text {lag }_{5}}=[.5, .5714, .6667, .8]$. The $\nu$-gap plots of the resulting ROMs are shown in Figure 14. It can be concluded that $p_{\text {lag }_{5}}$ gives the best results and the resulting number of lag states is 108 .

\section{Step 3: Reduction of the DLM aerodynamics}

In the third step, a linear balancing transformation matrix $T$ is computed for the 108-state aerodynamic model given by $A_{\text {lag }}, B_{\text {lag }}$ and $C_{\text {lag }}$ as in Equation 9. The reduced-order aerodynamic model is obtained by residualizing the states with the smallest Hankel singular values. Four cases are investigated, in which 1-, 2-, 3- and 4-state aerodynamic models are obtained. The $\nu$-gap results are shown in Figure 15.

It can be concluded, that the 1 -state aerodynamic model increases the $\nu$-gap value to unacceptable levels, while retaining more than 2 aerodynamic lag states does not lead to significant improvements. The 2 -state aerodynamic model is therefore used for the final ROM.

The resulting bottom-up ROM consists of 12 rigid body states, 18 structural dynamic states, 2 aerodynamic lag states and 24 actuator dynamic states. An important benefit of such a "bottom-up" modeling approach is that the physical meaning of the states is preserved. Consequently, the interpolation between the LPV grid points can be easily solved. 


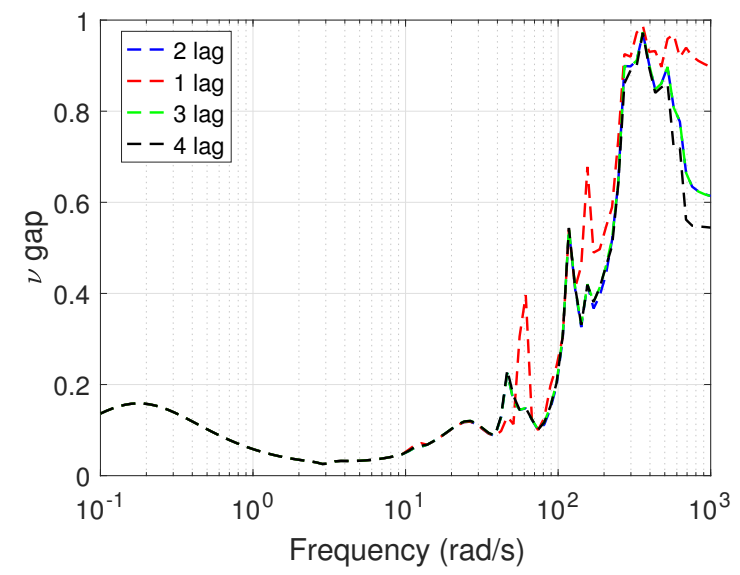

Figure 15. Maximal $\nu$-gap values of the lag state aerodynamics reduction

The resulting LPV model can be further reduced if necessary, for example by LPV balanced reduction 30 which is limited to systems with a relatively low dynamic order $31[32$

\section{B. Assessment of the reduced-order model (ROM)}

The objective of the proposed bottom-up modeling approach is to obtain a ROM suitable for the design of an active ASE control law that also performs well on the higher fidelity FOM. In the process of deriving the ROM, the main verification tool used is the $\nu$-gap metric. In addition to this, the pole migration, Bode plots and responses from numerical simulation of the ROM and FOM are compared to assess the accuracy of the derived ROM.

\section{Pole migration}

Figure 16 shows the pole migrations of the resulting ROM and Figure 17 compares the pole migrations of the ROM and FOM LPV systems. The high frequency poles are not shown in the figures for better visibility. The poles of both models migrate on a very similar trajectory. The full-order LPV model predicts flutter at $52 \mathrm{~m} / \mathrm{s}$ and $55 \mathrm{~m} / \mathrm{s}$, at frequencies of $50.2 \mathrm{rad} / \mathrm{s}$ and $45.8 \mathrm{rad} / \mathrm{s}$ respectively. The reduced-order LPV model predicts flutter at $52.5 \mathrm{~m} / \mathrm{s}$ and $56.5 \mathrm{~m} / \mathrm{s}$, at frequencies of $50.3 \mathrm{rad} / \mathrm{s}$ and $46 \mathrm{rad} / \mathrm{s}$ respectively. The accuracy of flutter speed and frequency of the ROM is sufficient for control design.

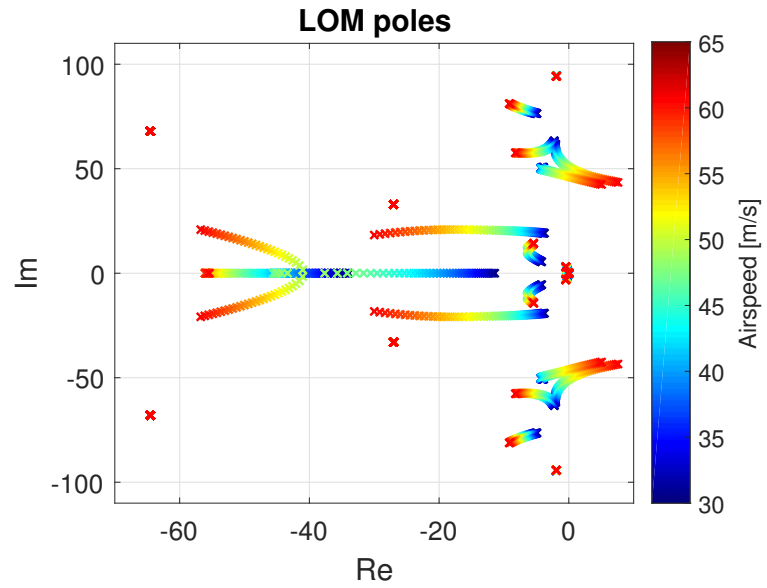

Figure 16. Pole migration of the ROM

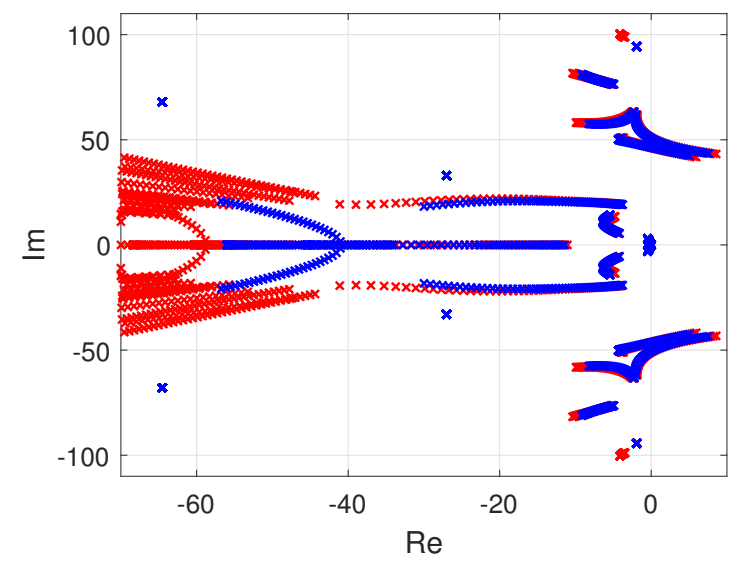

Figure 17. Pole migration of the ROM (blue) and FOM (red) 


\section{Bode diagram comparison}

Figures 18 and 19 depict Bode plots of the reduced- and full-order LPV models at $45 \mathrm{~m} / \mathrm{s}$ and $55 \mathrm{~m} / \mathrm{s}$ airspeeds. The ROM captures the input-output behavior of the FOM very well in the frequency range of interest. The accuracy of the ROM above $100 \mathrm{rad} / \mathrm{s}$ is visibly reduced.

\section{Time domain simulation results}

A time domain simulation is performed to compare the reduced-order nonlinear model with the full-order model. The two models are run in open-loop. The models are excited by applying $3^{\circ}$ doublets on the elevator. Additionally, a ramp signal is added to the trim throttle value. The simulation starts from trim condition at $V_{T A S}=50 \mathrm{~m} / \mathrm{s}$ and the speed is increased slightly above the first flutter speed. The inputs signals and responses of the ROM and FOM are shown in Figure 20. The two models show very similar behavior. One noticeable difference is the smaller damping of the ROM, which can be observed in the R6 IMU responses. This is probably caused by the reduced size of the lag states in the aerodynamics.

\section{Conclusions}

An aeroservoelastic modelling toolchain developed and applied within the FLEXOP project is presented in this paper.

A high-fidelity structural FE model forms the first step of the work-flow. The FE model is updated using results from a static test and GVT, followed by a static Guyan reduction. The aerodynamics is represented by VLM and DLM panel methods for the steady and unsteady parts respectively, which are corrected using results obtained from CFD methods. A spline model connects the structural FE model with the aerodynamic panel model to form the aeroelastic aircraft model. Dynamic models for the flight systems, external disturbances, sensors and actuators are added and the full-order non-linear aeroservoelastic model is obtained. This is linearized about different flight-points to obtain state-space representations of the linearized system. In the final step, reduced-order models based on an LPV framework are obtained using a bottom-up approach. Simulations show that the reduced-order controller design model is sufficiently accurate when compared with the full-order non-linear aeroservoelastic model.

\section{Acknowledgment}

The research leading to these results is part of the FLEXOP project. This project has received funding from the European Union's Horizon 2020 research and innovation program under grant agreement No. 636307.

\section{References}

${ }^{1}$ FLEXOP, "Flutter Free FLight Envelope eXpansion for ecOnomical Performance improvement (FLEXOP)," Project of the European Union, Project ID: 636307, 2015-2018.

${ }^{2}$ Stahl, P., Sendner, F.-M., Hermanutz, A., Rößler, C., and Hornung, M., "Mission and Aircraft Design of FLEXOP Unmanned Flying Demonstrator to Test Flutter Suppression within Visual Line of Sight," 17th AIAA Aviation Technology, Integration, and Operations Conference, American Institute of Aeronautics and Astronautics, Denver, Colorado, June 2017.

${ }^{3}$ Rozov, V., Hermanutz, A., Breitsamter, C., and Hornung, M., "Aeroelastic Analysis of a Flutter Demonstrator with a very Flexible High-Aspect-Ratio Swept Wing," IFASD - International Forum on Aeroelasticity and Structural Dynamics, Como, Italy, Oct. 2017.

${ }^{4}$ Binder, S., Wildschek, A., and De Breuker, R., "Aeroelastic Stability Analysis of the FLEXOP Demonstrator using the Continuous Time Unsteady Vortex Lattice Method," 2018 AIAA/ASCE/AHS/ASC Structures, Structural Dynamics, and Materials Conference, American Institute of Aeronautics and Astronautics, Kissimmee, Florida, Jan. 2018.

${ }^{5}$ Wuestenhagen, M., Kier, T., Meddaikar, Y. M., Pusch, M., Ossmann, D., and Hermanutz, A., "Aeroservoelastic Modeling and Analysis of a Highly Flexible Flutter Demonstrator," 2018 Atmospheric Flight Mechanics Conference, American Institute of Aeronautics and Astronautics, Atlanta, Georgia, June 2018.

${ }^{6}$ Sendner, F.-M., Stahl, P., Rößler, C., and Hornung, M., "Design of an Electric Actuated Airbrake for Dynamic Airspeed Control of an Unmanned Aeroelastic Research UAV," 2018 Aviation Technology, Integration, and Operations Conference, American Institute of Aeronautics and Astronautics, Atlanta, Georgia, June 2018.

${ }^{7}$ Luspay, T., Peni, T., and Vanek, B., "Control oriented reduced order modeling of a flexible winged aircraft," 2018 IEEE Aerospace Conference, IEEE, Big Sky, MT, March 2018, pp. 1-9.

${ }^{8}$ Sodja, J., Werter, N., and De Breuker, R., "Design of a flying demonstrator wing for manoeuvre load alleviation with 
$45 \mathrm{~m} / \mathrm{s}$

From: Aileron4L To: $\mathrm{q}$

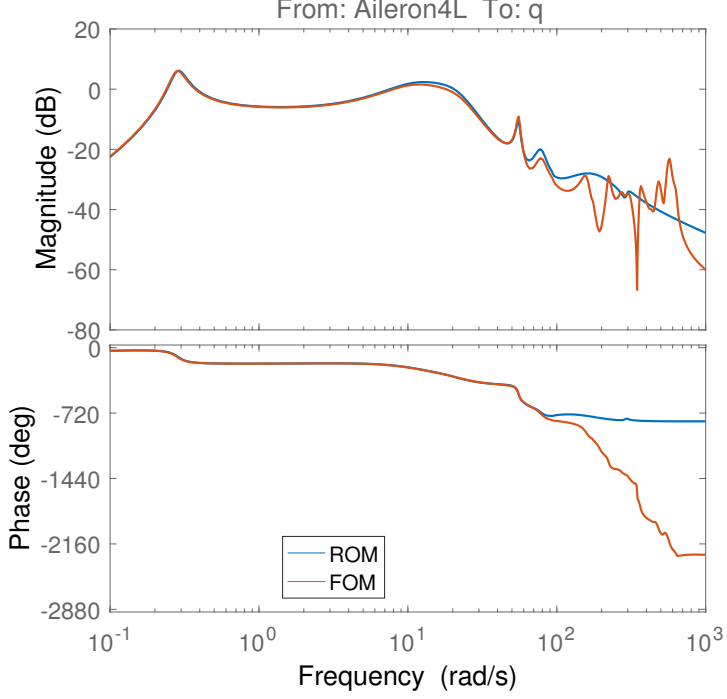

$45 \mathrm{~m} / \mathrm{s}$

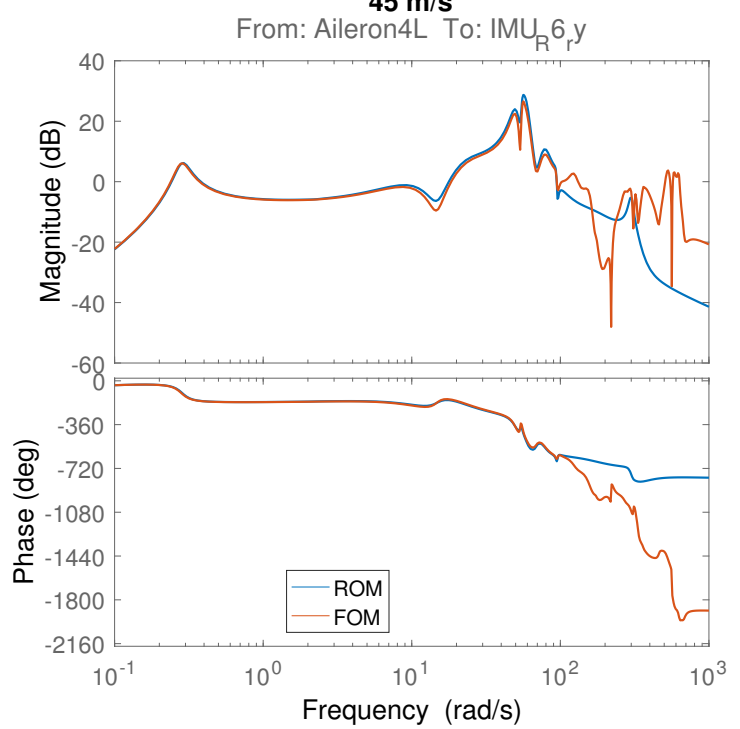

$45 \mathrm{~m} / \mathrm{s}$

From: Aileron4L To: $\mathrm{a}_{\mathrm{zB}}$

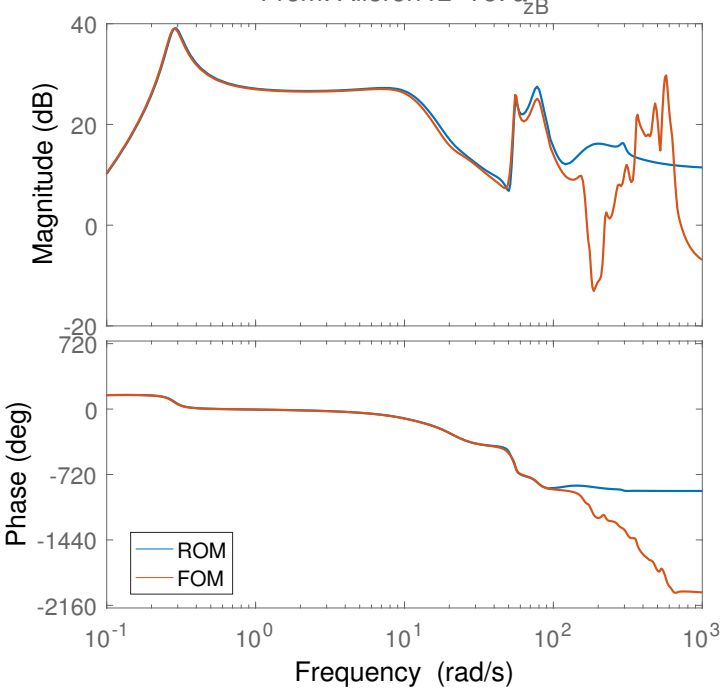

$45 \mathrm{~m} / \mathrm{s}$

From: Aileron4L To: IMU $6{ }_{\mathrm{a}} \mathrm{z}$

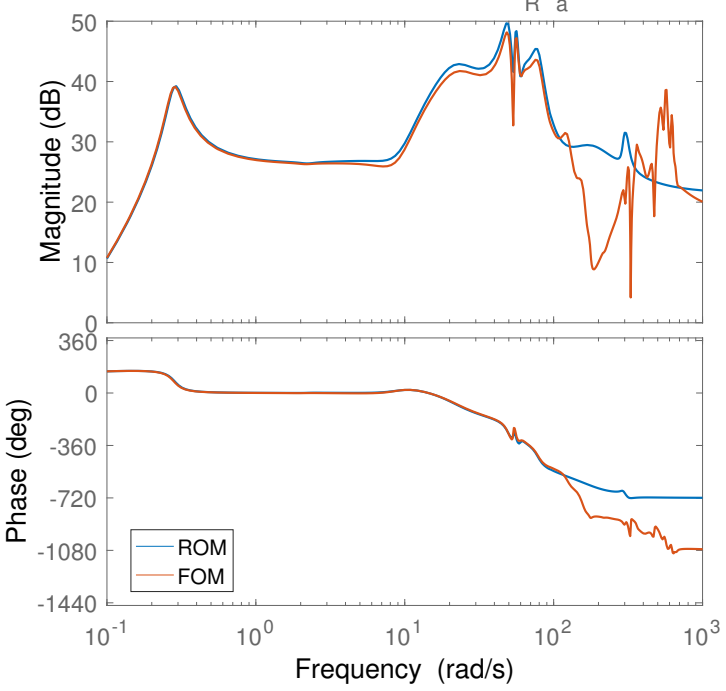

Figure 18. Bode plots of the ROM and FOM at $45 \mathrm{~m} / \mathrm{s}$ 
$55 \mathrm{~m} / \mathrm{s}$

From: Aileron4L To: $\mathrm{q}$

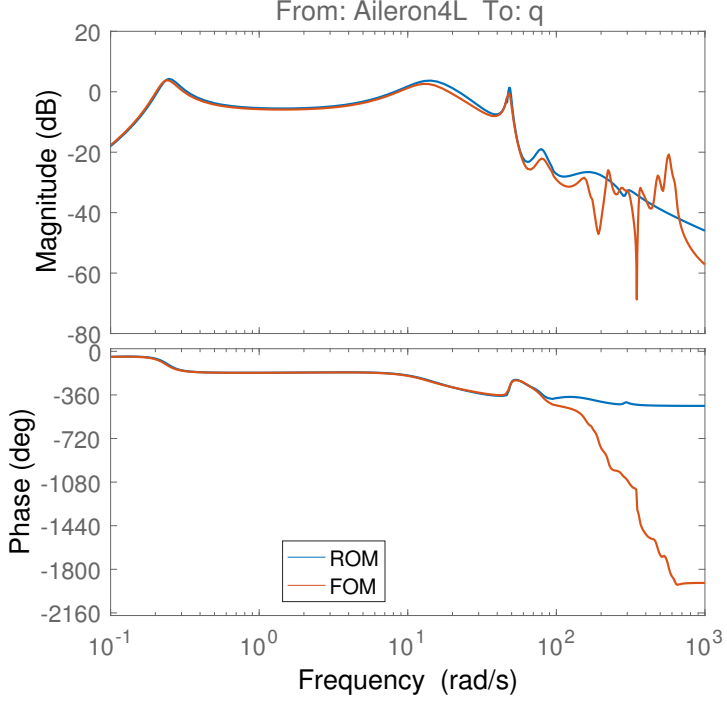

$55 \mathrm{~m} / \mathrm{s}$

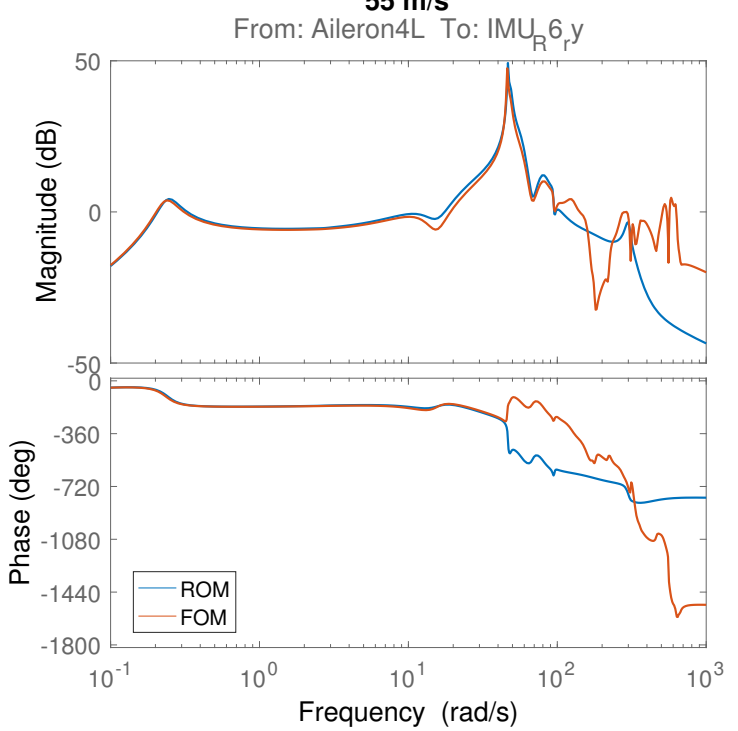

$55 \mathrm{~m} / \mathrm{s}$

From: Aileron4L To: $\mathrm{a}_{\mathrm{zB}}$

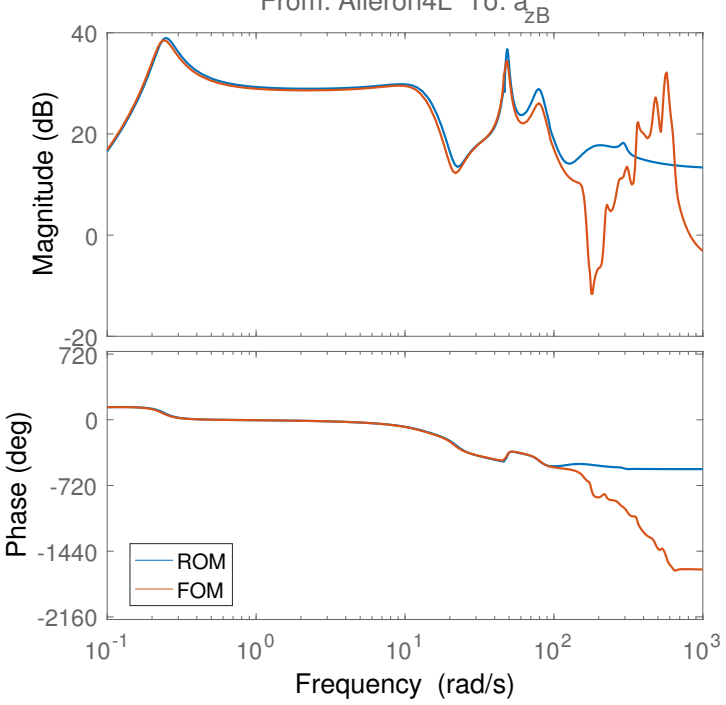

$55 \mathrm{~m} / \mathrm{s}$

From: Aileron4L To: $\operatorname{IMU}_{\mathrm{R}}{ }_{\mathrm{a}} \mathrm{z}$

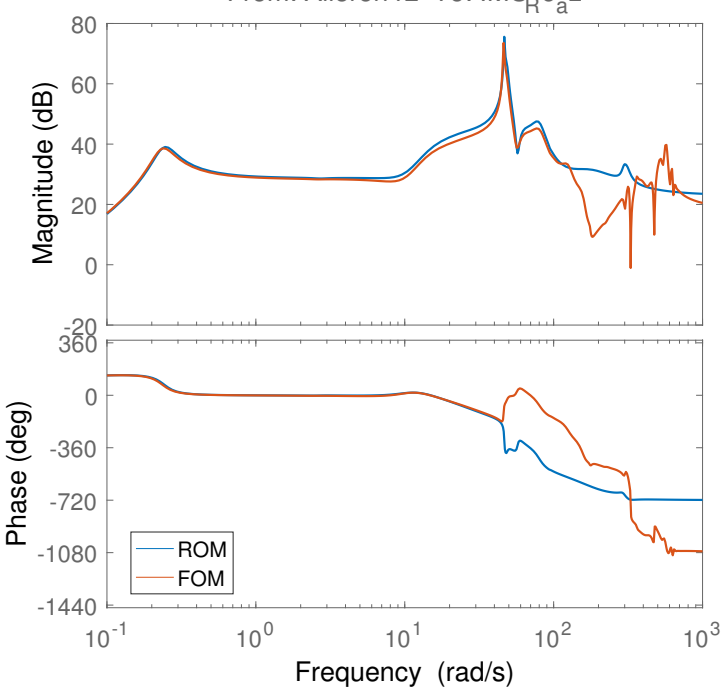

Figure 19. Bode plots of the ROM and FOM at $55 \mathrm{~m} / \mathrm{s}$ 

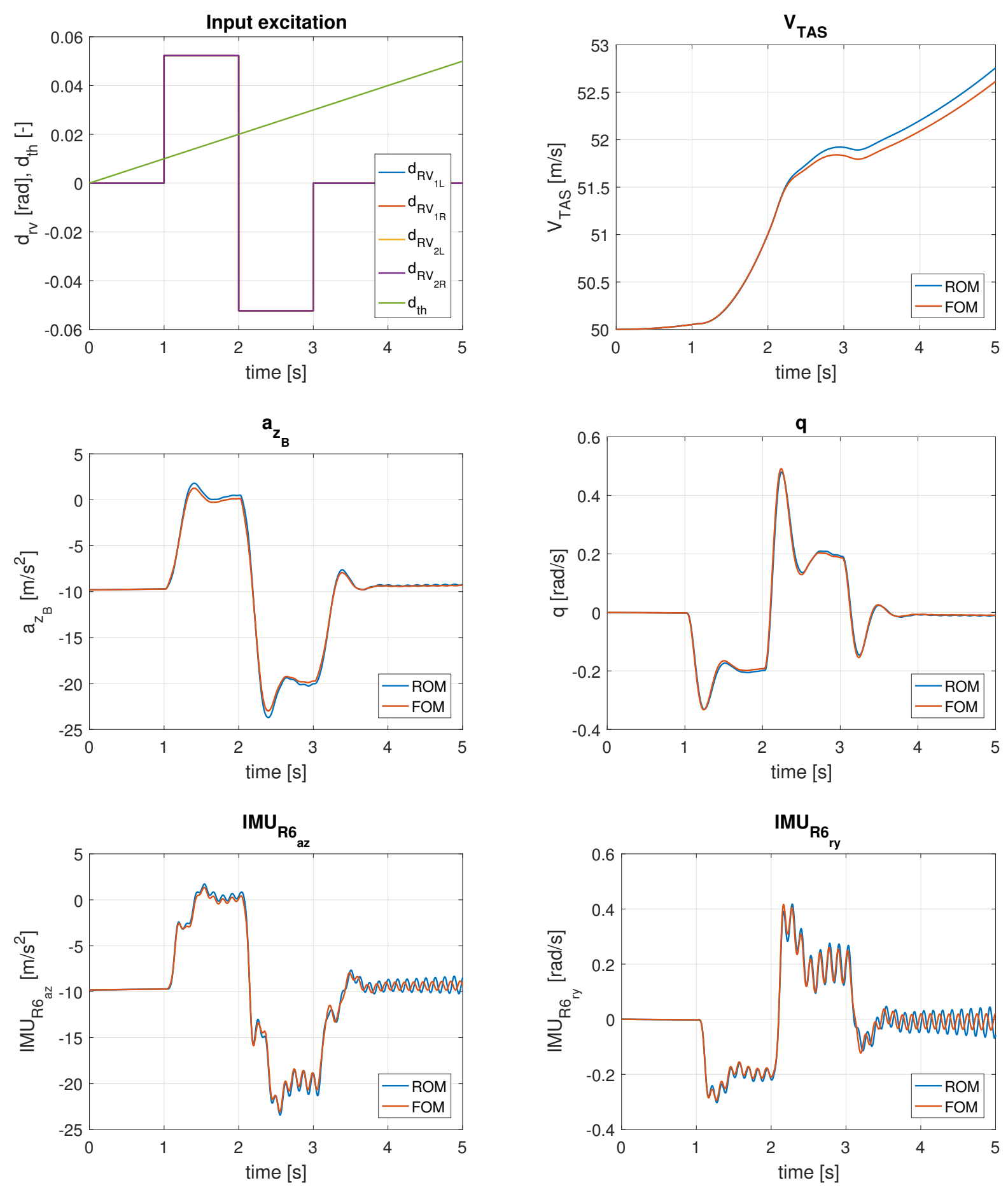

Figure 20. Nonlinear ROM and FOM responses 
cruise shape constraint," 2018 AIAA/ASCE/AHS/ASC Structures, Structural Dynamics, and Materials Conference, American Institute of Aeronautics and Astronautics, Kissimmee, Florida, Jan. 2018.

${ }^{9}$ Meddaikar, Y. M., Dillinger, J., Sodja, J., and De Breuker, R., "FLEXOP Application of aeroelastic tailoring to a flying demonstrator wing," DLRK 2018: Deutscher Luft- und Raumfahrtkongress, DGLR, Friedrichshafen, Germany, Sept. 2018.

${ }^{10}$ Roessler, C., Stahl, P., Sendner, F., Hermanutz, A., Koeberle, S. J., Bartasevicius, J., Rozov, V., Breitsamter, C., Hornung, M., Meddaikar, Y. M., Dillinger, J. K. S., Sodja, J., De Breuker, R., Koimtzoglou, C., Kotinis, D., and Georgopoulos, P., "Aircraft Design and Testing of FLEXOP Unmanned Flying Demonstrator to Test Load Alleviation and Flutter Suppression of High Aspect Ratio Flexible Wings," AIAA Atmospheric Flight Mechanics Conference, AIAA SciTech Forum. San Diego, California. Jan. 2019. (Submitted).

${ }^{11}$ Luspay, T., Ossmann, D., Baar, T., Teubl, D., Vanek, B., Pusch, M., Wüstenhagen, M., Kier, T., Waitman, S., Iannelli, A., Andres, M., and Lowenberg, M., "Flight control design for a highly flexible flutter demonstrator," AIAA Atmospheric Flight Mechanics Conference, AIAA SciTech Forum. San Diego, California. Jan. 2019. (Submitted).

${ }^{12}$ Kotikalpudi, A., Danowsky, B. P., Schmidt, D. K., Gupta, A., and Regan, C., "Real-Time Shape Estimation for a Small Flexible Flying-Wing Aircraft," AIAA Atmospheric Flight Mechanics Conference, AIAA SciTech Forum. San Diego, California. Jan. 2019. (Submitted).

${ }^{13}$ Zhao, W., Gupta, A., Miglani, J., Regan, C. D., Kapania, R. K., and Seiler, P. J., "Finite Element Model Updating of Composite Flying-wing Aircraft using Global/Local Optimization," AIAA Atmospheric Flight Mechanics Conference, AIAA SciTech Forum. San Diego, California. Jan. 2019. (Submitted).

${ }^{14}$ Schmidt, D. K., Danowsky, B. P., Kotikalpudi, A., Seiler, P. J., and Kapania, R. K., "Flight-Dynamics, Flutter Analysis, and Control of MDAO-Designed Flying-Wing Research Drones," AIAA Atmospheric Flight Mechanics Conference, AIAA SciTech Forum. San Diego, California. Jan. 2019. (Submitted).

${ }^{15}$ Ferede, E. and Abdalla, M., "Cross-sectional modelling of thin-walled composite beams," 55th AIAA/ASME/ASCE/AHS/ASC Structures, Structural Dynamics, and Materials Conference, American Institute of Aeronautics and Astronautics, National Harbor, Maryland, Jan. 2014.

${ }^{16}$ Klimmek, T., "Parameterization of Topology and Geometry for the Multidisciplinary Optimization of Wing Structures," CEAS 2009 - European Air and Space Conference, Manchester, United Kingdom, Oct. 2009, p. 9.

${ }^{17}$ Guyan, R. J., "Reduction of stiffness and mass matrices," AIAA Journal, Vol. 3, No. 2, Feb. 1965, pp. 380-380.

${ }^{18}$ Hofstee, J., Kier, T., Cerulli, C., and Looye, G., "A variable, fully flexible dynamic response tool for special investigations (VarLoads)," IFASD - International Forum on Aeroelasticity and Structural Dynamics, 2003.

${ }^{19}$ Kier, T. and Looye, G., "Unifying manoeuvre and gust loads analysis models," IFASD - International Forum on Aeroelasticity and Structural Dynamics, 2009.

${ }^{20}$ Tewari, A., Aeroservoelasticity: Modeling and Control, Springer - Verlag, 2015.

${ }^{21}$ Theis, J., Pfifer, H., and Seiler, P., "Robust Control Design for Active Flutter Suppression," AIAA Science and Technology Forum and Exposition, 2016, pp. Paper No. AIAA-2016-1751.

${ }^{22}$ Roger, K. L., Hodges, G. E., and Felt, L., "Active Flutter Suppression-A Flight Test Demonstration," Journal of Aircraft, Vol. 12, No. 6, jun 1975, pp. 551-556.

${ }^{23}$ Waszak, M. R. and Srinathkumar, S., "Flutter suppression for the active flexible wing - A classical design," Journal of Aircraft, Vol. 32, No. 1, jan 1995, pp. 61-67.

${ }^{24}$ Schmidt, D. K., "Stability Augmentation and Active Flutter Suppression of a Flexible Flying-Wing Drone," Journal of Guidance, Control, and Dynamics, Vol. 39, No. 3, mar 2016, pp. 409-422.

${ }^{25}$ Hjartarson, A., Seiler, P. J., Packard, A., and Balas, G. J., "LPV Aeroservoelastic Control using the LPVTools Toolbox," AIAA Atmospheric Flight Mechanics (AFM) Conference, American Institute of Aeronautics and Astronautics, Aug 2013.

${ }^{26}$ Shamma, J. S., Analysis and Design of Gain Scheduled Control Systems, Ph.D. thesis, Massachusetts Institute of Technology, Cambridge, 1988.

${ }^{27}$ Becker, G., Quadratic Stability and Performance of Linear Parameter Dependent Systems, Ph.D. thesis, University of California, Berkeley, 1993.

${ }^{28}$ Wu, F., Control of Linear Parameter Varying Systems, Ph.D. thesis, Univ. California, Berkeley, 1995.

${ }^{29}$ Takarics, B. and Seiler, P., "Gain Scheduling for Nonlinear Systems via Integral Quadratic Constraints," American Control Conference, 2015, pp. 811-816.

${ }^{30}$ Wood, G. D., Control of Parameter-Dependent Mechanical Systems, Ph.D. thesis, Univ. Cambridge, Cambridge, 1995.

${ }^{31}$ Theis, J., Takarics, B., Pfifer, H., Balas, G., and Werner, H., "Modal Matching for LPV Model Reduction of Aeroservoelastic Vehicles," AIAA Science and Technology Forum, 2015.

${ }^{32}$ Moreno, C., Seiler, P., and Balas, G., "Model Reduction for Aeroservoelastic Systems," Journal of Aircraft, Vol. 51, No. 1, 2014, pp. 280-290.

${ }^{33}$ Theis, J., Seiler, P., and Werner, H., "LPV Model Order Reduction by Parameter-Varying Oblique Projection," IEEE Transactions on Control Systems Technology, 2017.

${ }^{34}$ Poussot-Vassal, C. and Roos, C., "Generation of a reduced-order LPV/LFT model from a set of large-scale MIMO LTI flexible aircraft models," Control Engineering Practice, Vol. 20, No. 9, Sep 2012, pp. 919-930.

${ }^{35}$ Gozse, I., Luspay, T., Peni, T., Szabo, Z., and Vanek, B., "Model order reduction of LPV systems based on parameter varying modal decomposition," 2016 IEEE 55th Conference on Decision and Control (CDC), IEEE, Dec 2016.

${ }^{36}$ Luspay, T., Péni, T., Gözse, I., Szabó, Z., and Vanek, B., "Model reduction for LPV systems based on approximate modal decomposition," International Journal for Numerical Methods in Engineering, Vol. 113, No. 6, Oct. 2017 , pp. 891-909.

${ }^{37}$ Takarics, B., Vanek, B., Kotikalpudi, A., and Seiler, P., "Flight control oriented bottom-up nonlinear modeling of aeroelastic vehicles," 2018 IEEE Aerospace Conference, IEEE, March 2018.

${ }^{38}$ Vinnicombe, G., Measuring Robustness of Feedback Systems, Ph.D. thesis, Univ. Cambridge, Cambridge, 1993. 
This article has been cited by:

1. Manuel Pusch, Daniel Ossmann, Tamás Luspay. 2019. Structured Control Design for a Highly Flexible Flutter Demonstrator. Aerospace 6:3, 27. [Crossref]

2. Daniel Ossmann, Tamas Luspay, Balint Vanek. Baseline Flight Control System Design for an Unmanned Flutter Demonstrator 1-10. [Crossref] 